\title{
DEVELOPMENTAL AND NEUROLOGICAL SEQUELAE OF THE COMMON COMPLICATIONS OF PREGNANCY AND BIRTH
}

\author{
C. J. ROBERTS, M.D., D.P.H. \\ Lecturer in Social Medicine \\ Department of Social and Occupational Medicine, Welsh National School of Medicine
}

IT is important to understand the influence of obstetric complications on the neurological development of the infant and young child since the future planning of preventive and social paediatric services will depend largely on the clarification of this issue.

Since Little (1861) wrote about the influence of abnormal parturition, difficult labour, premature birth and asphyxia neonatorum on the mental and physical condition of the child, a continuing interest has been maintained by clinicians and research workers in this field of work. However, numerous hypotheses supported by numerous statistically significant relationships have failed to effect a medically significant general advance in this sphere, with a few notable exceptions such as oxygeninduced retrolental fibroplasia, anoxic damage to the cochlear nucleus and rubella embryopathy. Two main areas of difficulty are (1) that a study of the relationship between the obstetric environment and neuro-psychiatric morbidity in childhood remains a no-man's-land bordered by the specialities of paediatrics, obstetrics, pathology, neurophysiology, epidemiology and psychology, and (2) the rigorous demands of the epidemiological method over the last 10 to 20 years have substantially diluted, and in many cases nullified, the findings of a great many clinical studies in this field of work.

There is no doubt that obstetric complications carry an increased mortality.risk (De Haas-Posthuma, 1962; Butler and Bonham, 1963)-death of the fetus within a given time satisfies the epidemiological criteria of definition, but morbidity studies (which assess the damage to the surviving infant) are open to criticism unless strict definitions are available.

A well-planned series of retrospective studies on seven neuro-psychiatric disorders began in 1943 under the guidance of Knobloch and Pasamanick (1962) in Baltimore. The prenatal experiences of 4,000 children presenting with the certain defined neuro-psychiatric disabilities were compared with those of matched controls, and statistically signi- ficant relationships were found between obstetric abnormalities on the one hand and 'minimal cerebral damage', cerebral palsy, epilepsy, mental deficiency and reading disabilities on the other. These findings led to the proposal of the hypothesis of 'a continuum of reproductive casualty', which was further tested by a prospective investigation of 500 premature infants. Although Knobloch and Pasamanick (1962) have also emphasized the importance of socio-economic influences, there is no doubt that the findings of their Baltimore study have significantly influenced contemporary medical thought with respect to the clinical aetiology of the neuropsychiatric disorders.

Because of relative ease of definition, cerebral palsy has been an obvious choice for many epidemiological studies but as yet no clear picture has materialized. For example, studies by Sachs and Peterson (1890), Freud (1897), Osler (1899), Evans (1948), Asher and Schonell (1950), Anderson (1952), Tardieu, Klein, Held, and Trélat (1953), Courville (1954), Fuldner (1955), and Skatveldt (1958) showed positive correlations between cerebral palsy and birth hypoxia, but those by Collier (1924), Usdin and Weil (1952) and Keith, Norval, and Hunt (1953) could find no evidence of such an association.

By prospective analysis Rydberg (1932), Craig (1950), Burke (1954), and Eastman and DeLeon (1955) found positive correlations between cerebral palsy and birth hypoxia, but their findings were not corroborated by the prospective studies of Hannes (1914) and Campbell, Cheesman, and Kilpatrick (1950). A review of such works should consider critically the epidemiological methodology on which each study was based (definition of dependent and independent variables, sample selection, observer variation, test repeatability, etc); the sensitivity and specificity of the clinical criteria of abnormality (e.g., the clinical diagnosis of birth asphyxia and cerebral damage) in the light of present-day knowledge; and in many cases the specificity of certain 
pathological criteria of birth trauma and hypoxia on which the allocation of categories of prenatal and perinatal experience is made.

Animal experiments (Windle and Becker, 1943) have provided evidence of the harmful consequences of experimentally induced cerebral anoxia. However, a contemporary pathological viewpoint is that the human neonatal cerebral metabolism may well differ fundamentally from both that of the adult and that of the experimental animal, thus handicapping the interpretation of experimental findings and adult autopsy material (Laurence, 1969).

Prechtl (1967) studied the relation between neurological damage and obstetric complications in a group of 1,378 full-term new-born infants and found that, although neurological damage showed no association with any individual obstetric complication, it correlated well with a simple count of the number of obstetric complications occurring in one pregnancy. He considered such a count offered promise as a means of identifying those babies at risk of neurological damage. The frequency of co-existence of obstetric complications in one pregnancy has recently been discussed (Roberts, 1969).

It must be clear from this brief outline of the relationship between obstetric complications and infant development that we are a long way from an answer to the problem, yet in spite of this, administrative procedures have been put into operation purporting to screen early childhood handicaps using single categories of unfavourable obstetric experience as the screening test.

The further problem also exists that, even if a satisfactory screening test were available, population studies of the distribution of norms of infant neuropsychiatric function have not yet been undertaken. Therefore, with possibly the exception of gross deviations, we are as yet unable to say with any degree of certainty which patterns of behaviour are in fact abnormal.

In the present study the results of a scored neurological examination of a total infant population made during the second month of life, and of follow-up neurological and developmental examination made at one year, are related to the pregnancy and birth history of the said infants. The data were collected by one observer during two-and-ahalf years. A detailed analysis of the neurological and obstetric data will be found in earlier papers (Roberts, 1968, 1969).

\section{The SAmple}

\section{METHOD}

Three hundred and thirty-six infants out of a total birth population of 377 were examined; the mothers of 30 children were uncooperative, and 11 moved out of the area.

\section{NeUrological Examination In EarLy INFANCY}

Between 3 and 8 weeks of age all the infants were given a neurological examination which was scored by reference to a standarized neurological schedule (Roberts, 1968). The maximum total score was 50.

\section{NeUrological and Developmental Examination AT 1 YeAR}

Between 44 and 56 weeks of age all infants were given both a developmental assessment and an examination for neurological abnormality. The level of development was determined by using a developmental test (Griffiths, 1958) standardized on English children. The presence of neurological abnormality was determined by using a battery of 60 observations covering muscle tone, reflex activity, neuromotor patterns and special sensory function (Gesell and Amatruda, 1951; Knobloch ane Pasamanick, 1962).

\section{OBSTETRIC COMPLICATIONS}

Five obstetric complications were studiedvaginal bleeding necessitating bed-rest or admission to hospital, toxaemia, prolonged hyperemesis, anaemia and birth difficulties.* Data were collected by direct questioning of the mother at the infant's first neurological examination between 3 and 8 weeks of age.

The incidence and inter-relationship of pregnancy complications and birth difficulties studied in the sample were briefly as follows. Fifty-eight per cent of mothers in the sample had a normal pregnancy and delivery, $26 \%$ experienced one and $16 \%$ experienced two or more pregnancy and/or birth complications. Sixty per cent of mothers with prolonged hyperemesis also had other pregnancy complications or birth difficulties. Fifty-four per cent of all infants who experienced difficulties at birth also experienced pregnancy complications. Bleeding and toxaemia were frequently recurring themes-not only were they of numerical importance in themselves $(20 \%$ of all pregnancies) but they were associated with $30 \%$ of birth difficulties.

'Birth difficulties' was a heterogeneous group consisting of de liveries by forceps, breech or Caesarian section; multiple births; and birth asphyxia. 


\section{RESULTS}

Relation between Birth Difficulties and PregNANCY COMPLICATIONS AND NEUROLOGICAL SCORE IN EARLY INFANCY

Table I shows that the incidence of low neurological scores recorded between 3 and 8 weeks of age was higher for each group of obstetric complications compared with the whole sample. In the case of birth difficulties the difference is statistically significant. When the incidence of low neurological

TABLE I

PERCENTAGE DISTRIBUTION OF NEUROLOGICAL SCORES IN EARLY INFANCY RELATED TO PREGNANCY COMPLICATIONS AND BIRTH DIFFICULTIES

\begin{tabular}{|c|c|c|c|c|c|}
\hline \multirow{2}{*}{$\begin{array}{l}\text { Obstetric } \\
\text { Complication }\end{array}$} & \multicolumn{3}{|c|}{ Neurological Score } & \multirow{2}{*}{ No. } & \multirow{2}{*}{$\mathbf{P}$} \\
\hline & Up to 45 & $46-50$ & Total $(\%)$ & & \\
\hline $\begin{array}{l}\text { Bleeding } \\
\text { Toxaemia } \\
\text { Hyperemesis } \\
\text { Anaemia } \\
\text { Birth Difficulties } \\
\text { Whole sample }\end{array}$ & $\begin{array}{l}19 \cdot 4 \\
20 \cdot 8 \\
14 \cdot 3 \\
19 \cdot 0 \\
25 \cdot 0 \\
12 \cdot 2\end{array}$ & $\begin{array}{l}80 \cdot 6 \\
79 \cdot 2 \\
85 \cdot 7 \\
81.0 \\
75.0 \\
87 \cdot 8\end{array}$ & $\begin{array}{l}100 \\
100 \\
100 \\
100 \\
100 \\
100\end{array}$ & $\begin{array}{r}36 \\
48 \\
42 \\
21 \\
52 \\
336\end{array}$ & $\begin{array}{l}\text { N.S. } \\
\text { N.S. } \\
\text { N.S. } \\
\text { N.S. }\end{array}$ \\
\hline
\end{tabular}

scores in infants who experienced pregnancy complications and birth difficulties was compared with the incidence of low scores in infants who experienced birth difficulties alone, the former was found to be three times higher than the latter (Table II).

TABLE II

DISTRIBUTION OF LOW NEUROLOGICAL SCORES AMONG INFANTS WHO EXPERIENCED BIRTH DIFFICULTIES

\begin{tabular}{l|c|c|c}
\hline \multicolumn{1}{c|}{ Birth Difficulties } & \multicolumn{2}{|c}{ Neurological Score } \\
\cline { 2 - 4 } & Up to 45 & $46-50$ & Total \\
\hline $\begin{array}{l}\text { Following a normal pregnancy } \\
\text { Following pregnancy } \\
\text { complications }\end{array}$ & $3(12 \%$ & 21 & 24 \\
\hline Total & $10(36 \%)$ & 18 & 28 \\
\hline
\end{tabular}

$$
\mathbf{P}=0.05
$$

Relation Between BiRTH Difficulties and Pregnancy Complications and DeVelopmental and Neurological Status at 1 Year

Table III shows the mean developmental score (Griffiths, 1958) in each group of complications and the mean score for the whole sample. Each group of developmental scores was divided into "complicated' and 'uncomplicated' subgroups, the former representing infants who experienced the primary complication together with an additional complication of pregnancy and/or birth. (The anaemia group was not subdivided because of its small size.) In every group where this subdivision was made, the mean developmental score was found to be lower in the 'complicated' than in the 'uncomplicated' group. The mean scores for 'all bleeding', 'complicated bleeding' and 'complicated toxaemia' groups were significantly lower than the mean developmental score for the whole sample.

\section{TABLE III}

DEVELOPMENTAL SCORES AT 12 MONTHS IN RELATION TO PREGNANCY COMPLICATIONS AND BIRTH DIFFICULTIES

\begin{tabular}{|c|c|c|c|c|}
\hline \multirow{2}{*}{ Obstetric Complication } & \multicolumn{2}{|c|}{$\begin{array}{l}\text { Developmental } \\
\text { Score }\end{array}$} & \multirow{2}{*}{ No. } & \multirow{2}{*}{$\mathbf{P}$} \\
\hline & Mean & $\begin{array}{l}\text { Standard } \\
\text { Deviation }\end{array}$ & & \\
\hline $\begin{array}{l}\text { Bleeding } \\
\text { All bleeding } \\
\text { Complicated bleeding } \\
\text { Uncomplicated bleeding }\end{array}$ & $\begin{array}{l}96 \cdot 1 \\
95 \cdot 0 \\
97 \cdot 1\end{array}$ & $\begin{array}{l}6.8 \\
6.6 \\
6.9\end{array}$ & $\begin{array}{l}36 \\
19 \\
17\end{array}$ & $\begin{array}{c}\bullet \\
\text { N.S. }\end{array}$ \\
\hline $\begin{array}{l}\text { Toxaemia } \\
\text { All toxaemias } \\
\text { Complicated toxaemia } \\
\text { Uncomplicated toxaemia }\end{array}$ & $\begin{array}{l}97 \cdot 4 \\
95 \cdot 6 \\
99 \cdot 3\end{array}$ & $\begin{array}{l}7 \cdot 8 \\
8 \cdot 1 \\
7 \cdot 1\end{array}$ & $\begin{array}{l}48 \\
27 \\
21\end{array}$ & $\begin{array}{c}\text { N.S. } \\
\text { N.S. }\end{array}$ \\
\hline $\begin{array}{l}\text { Hyperemesis } \\
\text { All hyperemesis } \\
\text { Complicated hyperemesis } \\
\text { Uncomplicated hyperemesis }\end{array}$ & $\begin{array}{r}99 \cdot 2 \\
97.4 \\
103.0\end{array}$ & $\begin{array}{l}9.8 \\
9.6 \\
9.2\end{array}$ & $\begin{array}{l}42 \\
27 \\
15\end{array}$ & $\begin{array}{l}\text { N.S. } \\
\text { N.S. } \\
\text { N.S. }\end{array}$ \\
\hline $\begin{array}{l}\text { Anaemia } \\
\text { All anaemia }\end{array}$ & 96.9 & $11 \cdot 3$ & 21 & N.S. \\
\hline $\begin{array}{l}\text { Birth difficulties } \\
\text { All birth difficulties } \\
\text { Complicated birth difficulties } \\
\text { Uncomplicated birth difficulties }\end{array}$ & $\begin{array}{r}98 \cdot 6 \\
96 \cdot 2 \\
100 \cdot 6\end{array}$ & $\begin{array}{l}9 \cdot 7 \\
9 \cdot 8 \\
9 \cdot 5\end{array}$ & $\begin{array}{l}52 \\
27 \\
25\end{array}$ & $\begin{array}{l}\text { N.S.S. } \\
\text { N.S. } \\
\text { N.S. }\end{array}$ \\
\hline Whole sample & $99 \cdot 3$ & 8.9 & 336 & \\
\hline
\end{tabular}

The distribution of developmental scores for each complication group was compared with the distribution for the whole sample (Table IV). The proportion of infants with developmental scores below 97.5 in both the 'complicated bleeding' and the 'complicated toxaemia' groups was approximately twice that of the whole sample. The differences are significant. In the 'uncomplicated bleeding' and 'uncomplicated toxaemia' groups the proportion of low scores was increased, but not significantly so. The proportion of infants with scores below 97.5 in the "birth difficulties with pregnancy complications' group was $50 \%$ higher than for the whole sample. In the 'birth difficulties without pregnancy complications' group, however, the proportion with low scores was a little less than for the whole sample. 
TABLE IV

PERCENTAGE DISTRIBUTION OF DEVELOPMENTAL SCORES AT 12 MONTHS RELATED TO PREGNANCY COMPLICATIONS AND BIRTH DIFFICULTIES

\begin{tabular}{|c|c|c|c|c|c|c|}
\hline & \multicolumn{4}{|c|}{ Developmental Score } & \multirow{2}{*}{ No. } & \multirow{2}{*}{$\mathbf{P}$} \\
\hline & Up to 97.5 & $97 \cdot 5-102 \cdot 5$ & Over $102 \cdot 5$ & Total (\%) & & \\
\hline $\begin{array}{l}\text { Bleeding } \\
\text { All bleeding } \\
\text { Complicated bleeding } \\
\text { Uncomplicated bleeding }\end{array}$ & $\begin{array}{l}61 \cdot 2 \\
73 \cdot 7 \\
47 \cdot 1\end{array}$ & $\begin{array}{l}22 \cdot 2 \\
29 \cdot 4\end{array}<-$ & $\begin{array}{r}16 \cdot 6 \\
23 \cdot 5\end{array}$ & $\begin{array}{l}100 \\
100 \\
100\end{array}$ & $\begin{array}{l}36 \\
19 \\
17\end{array}$ & N.S. \\
\hline $\begin{array}{l}\text { Toxaemia } \\
\text { All toxaemia } \\
\text { Complicated toxaemia } \\
\text { Uncomplicated toxaemia }\end{array}$ & $\begin{array}{l}58 \cdot 4 \\
66 \cdot 7 \\
51 \cdot 8\end{array}$ & $\begin{array}{l}22 \cdot 9 \\
29 \cdot 6\end{array}<$ & $\begin{array}{r}18 \cdot 7 \\
18 \cdot 6\end{array}$ & $\begin{array}{l}100 \\
100 \\
100\end{array}$ & $\begin{array}{l}48 \\
27 \\
21\end{array}$ & $\begin{array}{l}\text { N.S. } \\
\text { N.S. }\end{array}$ \\
\hline $\begin{array}{l}\text { Hyperemesis } \\
\text { All hyperemesis } \\
\text { Complicated hyperemesis } \\
\text { Uncomplicated hyperemesis }\end{array}$ & $\begin{array}{l}28 \cdot 5 \\
29 \cdot 6 \\
33 \cdot 3\end{array}$ & $\begin{array}{l}40 \cdot 6 \\
48 \cdot 2\end{array}$ & $\begin{array}{r}30 \cdot 9 \\
22 \cdot 2\end{array}$ & $\begin{array}{l}100 \\
100 \\
100\end{array}$ & $\begin{array}{l}42 \\
27 \\
15\end{array}$ & $\begin{array}{l}\text { N.S. } \\
\text { N.S. } \\
\text { N.S. }\end{array}$ \\
\hline $\begin{array}{l}\text { Anaemia } \\
\text { All anaemias }\end{array}$ & $52 \cdot 4$ & & & 100 & 21 & N.S. \\
\hline $\begin{array}{l}\text { Birth difficulties } \\
\text { All birth difficulties } \\
\text { Complicated birth difficulties } \\
\text { Uncomplicated birth difficulties }\end{array}$ & $\begin{array}{l}38 \cdot 5 \\
48 \cdot 2 \\
28 \cdot 0\end{array}$ & $\begin{array}{l}26 \cdot 9 \\
29 \cdot 6 \\
24 \cdot 0\end{array}$ & $\begin{array}{l}34 \cdot 6 \\
22 \cdot 2 \\
48 \cdot 0\end{array}$ & $\begin{array}{l}100 \\
100 \\
100\end{array}$ & $\begin{array}{l}52 \\
27 \\
25\end{array}$ & $\begin{array}{l}\text { N.S. } \\
\text { N.S. } \\
\text { N.S. }\end{array}$ \\
\hline Whole sample & $34 \cdot 5$ & $31 \cdot 8$ & $33 \cdot 7$ & 100 & 336 & \\
\hline
\end{tabular}

The overall incidence of neurological abnormality at 1 year in the whole sample was found to be $6 \%$; the incidence of neurological abnormality in infants in each of the obstetric complication groups was as follows: bleeding $6 \%$, toxaemia $4 \%$, hyperemesis $5 \%$, anaemia $14 \%$, birth difficulties $8 \%$. None of the differences is statistically significant and it must be concluded that in this sample no relationship could be demonstrated between the presence of neurological abnormality at 1 year* and previous obstetric experience.

\section{Discussion}

The data from the majority of previous studies have been derived from infants who experienced selected complications (e.g., birth asphyxia) compared with matched controls. In the present investigation first a total infant population of 336 infants was studied and then the incidence of defects among those children who experienced certain pregnancy complications and/or birth difficulties was compared with the incidence of similar defects among the whole sample. It was felt that, in this way, a true picture of the difference in a defined community could be obtained.

INTER-Relation BeTWEen Pregnancy COMPliCATIONS AND BIRTH Difficulties aNd NeuroLogical Findings duRING Second Month of Life

The results shown in Table I would appear to demonstrate a clear relationship between birth difficulties and early neurological defect. However, attention needs to be drawn to the co-existence of pregnancy with birth complications discussed in an earlier paper (Roberts, 1969) and in particular to the finding which showed that $54 \%$ of all infants with birth difficulties also experienced complications of pregnancy.

When the findings in Tables I and II are considered together the significant increase in low neurological scores among children with birth difficulties almost certainly derives from those infants who also experienced pregnancy complications. In practice this could mean that the relationships which exist between birth difficulties and early neurological defect may not be direct, as is commonly thought, but are indirect, through an association with complications of pregnancy. This finding is relevant to the selection of 'at risk' factors used in the early detection of handicapped children.

It may also be important, in view of the high incidence of toxaemia and bleeding during pregnancy, that the findings of an increased proportion of low neurological scores among infants who experienced these complications should be further examined by epidemiological studies using larger samples.

-Determined by clinical examination, and therefore distinct from the assessment of development, see page 34 . 
Inter-Relation between Pregnancy ComplicaTIONS AND BIRTH Difficulties AND Neurological FunCTION (DETERMINED BY DEVELOPMENTAL ASSESSMENT AND Clinical EXamination) at 1 Year

Two pregnancy complications were found to be significantly related to developmental delay (but not to neurological abnormality) at 1 year-these were bleeding and toxaemia. Knobloch, Rider, Harper, and Pasamanick (1956) and Ten Berge (1961) have suggested that it is the potential hypoxia producing abnormalities occurring in late pregnancy (such as antepartum haemorrhage and/or toxaemia) which are the greatest hazards to the fetus.

The association between birth difficulties and low neurological score which was present at 2 months had disappeared by 12 months. It is unlikely that the examination at 1 year was too insensitive to detect any difference, as it was more detailed than the earlier assessment and was sufficiently sensitive to detect an association with bleeding and toxaemia. It may therefore be that the neurological sequelae of birth difficulties are temporary and only present during early infancy. These findings may be of significance in the diagnosis and management of children with neuro-psychiatric disorders. There is a tendency to label children with behaviour disorders, speech defects and specific learning difficulties as 'brain injured' if they have a history of a complicated or difficult birth. The findings of this study suggest that infants who experience such complications do not show evidence of neurological defect at 1 year unless they also experienced third trimester bleeding or toxaemia during pregnancy.

The potential significance of the co-existence, or summation, of individual obstetric complications is emphasized in Tables III and IV. At 2 months there was evidence of the summation of the effects of both pregnancy and birth complications, to produce an increase in the incidence of low neurological scores. At 1 year the effects of summation of pregnancy complications was clearly associated with an increased incidence of developmental delay (but not with neurological abnormality).

These findings may have practical significance in relation to the existing 'at risk' procedure. Whilst there is some evidence to suggest an increased incidence of defects among certain pregnancy and birth 'at risk' groups, this could possibly be explained either by the occurrence of a few significant 'high risk' conditions or by the summation of factors which by themselves are associated with little or no subsequent risk of neurological damage to the infant (Prechtl, 1967).

The strength of the association between 'at risk' groups and subsequent neurological handicaps needs to be investigated much more closely. Reference to Tables III and IV shows that even relationships between pregnancy and/or birth complications and developmental delay, which are (statistically speaking) highly significant, are in practice not nearly strong enough to form a basis for a screening procedure - if the prevalence of a certain complication in all confinements is $5 \%$, then the handicap must occur 16 times more frequently in that complication group than in all confinements to achieve a sensitivity level of $80 \%$ (Richards and Roberts, 1967). In this study the incidence of low developmental scores for the complications with the highest associations (bleeding and toxaemia) was only twice that for the whole sample. Furthermore, no evidence could be found of any significant association between the obstetric complications studied and neurological abnormality.

It would thus appear that, in practice, it is very difficult to demonstrate any significant relationship between the common pregnancy and/or birth complications on the one hand and developmental and neurological abnormality at 1 year on the other, even when the latter has been assessed using very detailed and time-consuming techniques. This finding would appear to suggest that the selection of children by single categories of obstetric experience is not an effective method of isolating children at risk to neuro-psychiatric handicaps from the general infant population.

\section{SUMMARY}

The neurological and developmental status of 336 infants $(89 \%$ of the entire birth population of a defined area in South Wales) was assessed by one observer (the writer) when each child was 2 months old and 12 months old, and the results were related to the pregnancy and birth histories of the infants. The findings suggest that:

The relationships between neurological status and certain complications of birth may not be direct, as has hitherto been thought, but are possibly indirect through the association between neurological status and certain complications of pregnancy.

Correlations between obstetric 'at risk factors' and subsequent handicap may be due either to the occurrence of a very few significant 'high risk' conditions, or to the summation of factors which by themselves are not significantly associated with subsequent neurological damage to the infant.

Where statistically significant associations between individual obstetric complications and subsequent neurological status can be demonstrated, the difference in incidence of handicaps among 
children experiencing these complications and among the general infant population is not great enough to provide an acceptably sensitive screening procedure.

During the preparation of this paper the writer was working on research projects financially supported by the Association for the Aid of Crippled Children, New York.

\section{REFERENCES}

ANDERSON, G. W. (1952). Obstetrical factors in cerebral palsy. J. Pediat., 40, 340.

Asher, P., and Schonell, F. E. (1950). A survey of 400 cases of cerebral palsy in childhood. Arch. Dis. Childh., $25,360$.

BURKE, J. B. (1954). The prognostic significance of neonatal convulsions. Ibid., 29, 342.

Butler, N. R., and Bonham, D. G. (1963). Perinatal Mortality: The First Report of the 1958 Perinatal Mortality Survey (National Birthday Trust Fund). Livingstone, Edinburgh and London.

Campbell, W. A. B., Chireseman, E. A., and KILPATRICK, A. W. (1950). The effects of neonatal asphyxia on physical and mental development. Arch. Dis. Childh., 25, 351.

CollirR, J. S. (1924). The pathogenesis of cerebral diplegia. Proc. roy. Soc. Med., 17, Section of Neurology, p. 1.

Courvilue, C. B. (1954). Cerebral Palsy. A brief introduction to its history, etiology, and pathology. San Lucas Press, Los Angeles.

CraIG, W. S. (1950). Intracranial irritation in the newborn: immediate and long term prognosis. Arch. Dis. Childh., 25, 325.

De Haas-Posthuma, J. H. (1962). Perinatele Sterfte in Nederland. Onderzoek naar Factoren, die de Perinatale Sterfte Beinvloden. Van Gorcum, Assen.

Eastman, N. J., and Deleon, M. (1955). The etiology of cerebral palsy. Amer. J. Obstet. Gynec., 69, 950.

Evans, P. R. (1948). Antecedents of infantile cerebral palsy. Arch. Dis. Child., 23, 213.

FreUd, S. (1897). Die infantile Cerebrallähmung. In Specielle Pathologie und Therapie, ed. H. Nothnagel, Band IX, II. Theil, II. Abtheilung. Hölder, Vienna.

FULDNER, R. V. (1955). Cerebral palsy: where next? Arch. Neurol. Psychiat. (Chic.), 74, 267.

Gesell, A., and AmatrudA, C. (1941). Developmental Diagnosis. Hoeber, New York.

GRIFFTrHS, R. G. (1958). The Abilities of Babies. London University Press.

Hannes, W., quoted by Manton, W. P. (1914). Asphyxia neonatorum and its sequelae. N.Y. St.J.Med., 14, 302.
Keith, H. M., Norval, M.A., and Hunt, A. B. (1953). Neurological lesions in relation to the sequelae of birth injury. Neurology (Minneap.), 3, 139.

KNOBLOCH, H., RIDER, R., HARPER, P., and PASAMANick, B. (1956). Neuropsychiatric sequelae of prematurity: A longitudinal study. J. Amer. med. Ass., 161, 581. , Pasamanick, B. (1962). The developmental behavioral approach to the neurologic examination in infancy. Child Develop., 33, 181.

LAURENCE, K. M. (1969). Personal communication.

LITTLE, W. J. (1861). On the influence of abnormal parturition, difficult labours, premature birth, and asphyxia neonatorum on the mental and physical condition of the child, especially in relation to deformities. Trans. obstet. Soc., Lond., 3, 293.

Osler, W. (1899). The Cerebral Palsies of Children. A Clinical Study for the Infirmary for Nervous Diseases. Blakiston, Philadelphia.

PrechtL, H. F. R. (1967). Neurological sequelae of prenatal and perinatal complications. Brit. med. J., 4, 763.

Richards, I. D. G., and RoberTs, C. J. (1967). The 'At risk' infant. Lancet, $2,1151$.

ROBERTS, C. J. (1968). The distribution of neurological signs in early infancy. Population study: In 'Studies in Infancy', p. 55. Clinics in develop. Med., No. 27. Spastics International Medical Publications, and Heinemann, London.

- (1969). The incidence of and relation between the common complications of pregnancy and delivery. Brit.J. prev. soc. Med., 23, 128.

RYDBERG, E. (1932). Cerebral injury in new-born children consequent on birth trauma; with an inquiry into the normal and pathological anatomy of the neuroglia. Acta. path. microbiol. scand. Suppl., 10.

SaChs, B., and Peterson, F. (1890). A study of cerebral palsies of early life based upon an analysis of 140 cases. J. nerv. ment. Dis., 17, 295.

Skatveldr, M. (1958). Cerebral palsy, a clinical study of 370 cases. Acta. paediat. (Uppsula), 46, Suppl. 111.

Tardiru, G., Klein, M. R., Held, J. P., and Trélat, J. (1953). 'Fréquence de l'apnée de la naissance dans les antécédents des encéphalopathies infantiles'. Rev. neurol., 89, 22.

TEN BERGE, B. S. (1961). The influence of the placenta on cerebral injuries. Cerebr. Palsy Bull., 3, 323.

UsDIN, G. L., and WeIL, M. L. (1952). Effect of apnea neonatorum on intellectual development. Pediatrics, 9, 387.

Windle, W. F., and Becker, R. F. (1943). Asphyxia neonatorum. An experimental study in the guineapig. Amer. J. Obstet. Gynec., 45, 183. 